\title{
Socio-Emotional Status, Education, and Time-Discounting in Japanese Non-Smoking Population: A Multi-Generational Study
}

\author{
Shoko Yamane ${ }^{1}$, Taiki Takahashi ${ }^{2}$, Akiko Kamesaka $^{3}$, Yoshiro Tsutsui ${ }^{4}$, Fumio Ohtake ${ }^{5}$ \\ ${ }^{1}$ Faculty of Economics, Kinki University, Osaka, Japan \\ ${ }^{2}$ Department of Behavioral Science, Center for Experimental Research in Social Sciences, \\ Hokkaido University, Hokkaido, Japan \\ ${ }^{3}$ School of Business Administration, Aoyama Gakuin University, Tokyo, Japan \\ ${ }^{4}$ Graduate School of Economics, Osaka University, Osaka, Japan \\ ${ }^{5}$ Institute of Social and Economic Research, Osaka University, Osaka, Japan \\ Email: taikitakahashi@gmail.com
}

Received November $18^{\text {th }}, 2012$; revised December $19^{\text {th }}, 2012$; accepted January $11^{\text {th }}, 2013$

\begin{abstract}
Recent studies in behavioral economics and neuroeconomics have revealed that emotion affects impulsivity in intertemporal choice. We examined the roles of socio-emotional status (i.e., perceived stress, depression, quality of sleep, loneliness) in temporal discounting behavior by Japanese non-smokers in a generation-specific manner $(20-70 \mathrm{~s})$ with a relatively large sample size $(\mathrm{N}=3450)$. We observed that 1$)$ both men and women are the most impulsive in their $60 \mathrm{~s} ; 2$ ) education has a negative impact on impulsivity in men aged $40-49$ and women aged $50-59 ; 3$ ) perceived stress has a negative impact on impulsivity in men aged 60 - 69; and 4) sleeplessness has negative and positive impacts on impulsivity in men aged 40 - 49 and women aged 30 - 39, respectively. Biological and social factors underlying observed findings are discussed.
\end{abstract}

Keywords: Time Discounting; Impulsivity; Stress; Depression; Emotion; Behavioral Economics

\section{Introduction}

Because temporal discounting behavior (intertemporal choice; preference for smaller sooner rewards over larger later ones) influences one's decisions, economists and neuroeconomists have shown tremendous interest in investigations into temporal discounting (Frederick, Loewenstein, \& O’Donoghue, 2002; Takahashi, 2009). Recently, roles of affect in temporal discounting behavior have been drawing much attention in behavioral economics and neuroeconomics (Ifcher \& Zarghamee, 2011; Löckenhoff, O’Donoghue, \& Dunning, 2011; McClure, Laibson, Loewenstein, \& Cohen, 2004). Specifically, Ifcher and Zarghamee (2011) demonstrated that mild positive affect significantly reduced impulsivity in intertemporal choice. Löckenhoff et al. (2011) reported that non-emotional intertemporal choice is reduced by age; while emotional intertemporal choice is insensitive to age. However, these studies examined only positive and/or disruptive (i.e., "visceral"; Loewenstein, 1996) emotions' effect on intertemporal choice.

\section{Emotion and Intertemporal Choice}

In the rapidly evolving field of neuroeconomics (Ernst, 2012; Loewenstein, Rick, \& Cohen, 2008; Phillips, Kim, \& Lee, 2012; Takahashi, 2009), effects of stress and depression on intertermporal choice have been examined (Takahashi, 2004; Takahashi et al., 2008a; Takahashi, Shinada, Inukai, Tanida, Takahashi, Mifune, Takagish, Horita, Hashimoto, Yokota, Kameda, \& Yamagishi, 2010), in relation to altered functioning of the stress system (i.e., Hypothalamic-pituitary-adrenal (HPA) axis and sympatho-adrenal medullar (SAM) system) and catecholamine/monoamine (dopaminergic and serotonergic) systems.
Takahashi and colleagues have previously observed that depressed patients are impulsive in the near future (Takahashi et al., 2008), and low cortisol (a human stress steroid hormone) levels were associated with impulsive intertemporal choice by men (Takahashi, 2004), salivary alpha-amylase (a non-invasive biomarker of SAM activation) is negatively related to impulsivity in both men and women (Takahashi et al., 2010). Also, a reduction in serotonergic activities increases impulsivity in intertemporal choice (Schweighofer, Bertin, Shishida, Okamoto, Tanaka, Yamawaki, \& Doya, 2008). These findings indicate that negative affect, as well as positive affect, influences temporal discounting behavior. However, to date, no study examined the roles of negative affect (especially, social emotions) in intertemporal choice in a large sample. Concerning social emotions, a recent neuroendocrinological study observed that loneliness increased impulsivity via biological pathways distinct from the signaling pathways in which testosterone affects impulsivity (Fujisawa, Nishitani, Ishii, \& Shinohara, 2011). Also, recent studies in health economics asked effect of loneliness on health and cognitive functioning in relation to retirement from labor markets (Coe \& Zamarro, 2011; Bonsang, Adam, \& Perelman, 2012). Therefore, it may have implications for both labor and health economics to investigate the role of loneliness in impulsivity in intertemporal choice.

\section{Age and Intertemporal Choice}

In addition to the roles of affect in intertemporal choice, the effect of age on intertemporal choice has been studied (Green, Fry, \& Myerson, 1994; Read \& Read, 2004; Loeckenhoff, 2011; Steinberg, Graham, O’Brien, Woolard, Cauffman, \& Banish, 
2009). Green et al., (1994) reported that temporal discounting was highest for children and lowest for older adults; in contrast, Read and Read (2004) observed that older people discount more than younger people and that middle aged people discount less than either group. Apparently, more studies with a large sample size regarding the relationship between age and temporal discounting are needed.

\section{Education and Intertemporal Choice}

Education may lower endogenous time-discount rate, because economists Becker and Mulligan (1997) argue that education can be understood as an investment in patience. Education can be understood as a tool that helps people to perceive future pleasures as less remote. In neuroeconomics, Berns, Laibson, and Loewenstein (2007) have emphasized the role of anticipation of future events in making choices whose consequences play out over time. Also, Peters and Büchel (2010) demonstrated that episodic future thinking reduces impulsivity in intertemporal choice, via cognitive function-related brain regions. Kirby, Winston, and Santiesteban (2005) reported that high grades in the college student are associated with patience in intertemporal choice (lowered time-discount rate). Because education systems differ across countries and generations, it is important to examine the relationship between education and temporal discounting in Japan with multiple-generations.

Some studies in labor economics have examined the roles of sex in economic decision (Fehr-Duda, De Gennaro, \& Schubert, 2006; Kimmo \& Brent, 2010) because there are large differences not only in the relative compensation, but also in the presence of women in the highest paid jobs (e.g., Azmat, Güell, \& Manning, 2004; Arulampalam, Booth, \& Bryan, 2007). Because the movement of women into the Japanese society has changed in several decades, it may be interesting to see the relationship between intertemporal choice and sex over generations.

\section{Sleep and Intertemporal Choice}

In both behavioral economics and neuroeconomics, effect of sleep deprivation on economic decision-making has been attracting attention, because effect of sleep deprivation on impulsivity is important in considering workplace safety (Acheson, Richards, \& de Wit, 2007; Reynolds \& Schiffbauer, 2004a; Venkatraman, Huettel, Chuah, Payne, \& Chee, 2011). Reynolds and Schiffbauer (2004b) reported that sleep deprivation increased impulsivity in intertemporal choice. Menz, Büchel, and Peter (2012) demonstrated that sleep deprivation altered neural processing underlying decision under risk. It is therefore important to examine the effect of sleeplessness on intertemporal choice in large samples.

\section{Intertemporal Choice and Field Behavior}

With respect to the relationships between impulsivity in intertemporal choice and field behavior, a recent behavioral economic study (Chabris, Laibson, Morris, Schuldt, \& Taubinsky, 2008) demonstrated that time-discount rate measured in the laboratory could predict various types of field behaviors (e.g., exercise, BMI, smoking). Hence, it can be said that assessment of time-discount rates in multi-generational Japanese population may be important for a better understanding of Japanese economic situations (e.g., gender gap in the labor market, in- come inequality over generations, pension problems). In the investigations into the relationships between Socio-emotional status, education, and time-discounting, it is important to exclude the habitual smokers, because chronic nicotine intake is associated with an increase in impulsivity in intertemporal choice for gain in Japanese people (Ohmura, Takahashi, \& Kitamura, 2005).

Overall, the present study examined the relationships of various types of socio-demographic variables to impulsivity in intertemporal choice in non-smokers. This study is the first to examine this in a large sample. It is expected that relationships between the variables and impulsivity in intertemporal choice may vary across generations.

\section{Methods}

\section{Data}

Our data were obtained from "Survey of Living Preferences and Satisfaction" conducted by the 21st Century COE program of Osaka University in February 2011. This survey consists of 100 questions about detailed data on individual attributes. 5386 Japanese men and women between the ages of 20 and 65 were chosen by two-stage sampling and surveyed by the visit-replacement method.

\section{Assessment of Time-Discount Rate}

The key variable, time discounting, is obtained by following procedure. The respondents were told to choose between two options, "A" and "B". The respondent receives JPY 10,000 (around USD 120) today when he chooses option " $A$ ", while he receives a different amount in seven days when he chooses option "B" . This question consists of nine choices. For example in sixth choice, the respondents compare JPY 10,000 today to JPY 10,383 (around USD 125) in seven days. In this case, choosing option " $\mathrm{B}$ " instead of option " $\mathrm{A}$ " is the same as receiving $200 \%$ of the annual interest rate.

The questionnaire is presented in Table $\mathbf{1}$, where the amount received under option " $A$ " is specified as JPY 10,000 and the imputed interest rate for option "B" changes from $-10 \%$ to $5000 \%$.

\section{Table 1.}

Questionnaire to elicit time-discount rate. Suppose you have two mutually-exclusive options to receive some money. You may choose Option "A", to receive 10,000 JPY in two days; or Option "B", to receive a different amount in nine days. Compare the amounts and delay until its receipt in Option "A" with Option "B" and indicate which option you would prefer for each pair of all nine choice pairs.

\begin{tabular}{ccccc}
\hline $\begin{array}{c}\text { Option A } \\
\text { Receipt in Today) }\end{array}$ & $\begin{array}{c}\text { Option B } \\
\text { (Receipt in 7 days) }\end{array}$ & $\begin{array}{c}\text { Interest rate } \\
\text { (Annual) }\end{array}$ & \multicolumn{2}{c}{ Circle A or B } \\
\hline JPY 10,000 & JPY 9980 & $-10 \%$ & A & B \\
JPY 10,000 & JPY 10,000 & $0 \%$ & A & B \\
JPY 10,000 & JPY 10,029 & $10 \%$ & A & B \\
JPY 10,000 & JPY 10,076 & $40 \%$ & A & B \\
JPY 10,000 & JPY 10,191 & $100 \%$ & A & B \\
JPY 10,000 & JPY 10,383 & $200 \%$ & A & B \\
JPY 10,000 & JPY 10,575 & $300 \%$ & A & B \\
JPY 10,000 & JPY 11,917 & $1000 \%$ & A & B \\
JPY 10,000 & JPY 195,689 & $5000 \%$ & A & B \\
\hline
\end{tabular}

${ }^{1}$ The exchange rate was about $\$ 1=¥ 83$ at February 2011 . 
The authors expected that the respondents would choose option " $\mathrm{A}$ " at low interest rates, but as the imputed interest rate rises, the authors expected they would ultimately switch to option " $\mathrm{B}$ " at a certain critical high rate. The individual respondents' discount rates can be inferred by estimating the interest rate at which respondents are indifferent between the delayed receipt of option " $\mathrm{B}$ " and the more immediate receipt of option "A".

The present study employed the procedures of measurement and analysis of time-discount rate similar to the authors' previous study (Ikeda, Kang, \& Ohtake, 2010; Kimball, Sahm, \& Shapiro, 2008). The authors estimated the gross discount rate for each respondent according to a lognormal distribution function. This estimation enables us to obtain the interest rates between which he switched his choice from option " $A$ " to "B". for each respondent, including those who stuck to option " $A$ " or " $B$ ". It is to be noted that the authors utilized logged gross time-discount rate as a dependent variable, following our previous study.

\section{Assessment of Education}

The authors assessed the respondents' education level by four categories. The variable of education takes 1) if the respondent graduated primary or middle school $(\mathrm{N}=539) ; 2)$ if graduated high school or two-year college (including those who left college without a diploma; $\mathrm{N}=3417$ ); 3 ) if graduated fouryear college (including those who left graduate school without master degree; $\mathrm{N}=1225$ ); and 4 ) if graduated higher than master's course $(\mathrm{N}=102)$.

\section{Assessment of Socio-Emotional Status and Sleeplessness}

The socio-emotional status are obtained, with Likert scales, by the degree of agreement for the following sentences; "I've been feeling stressed lately", "I've been feeling depressed lately", "I've been feeling lonely lately", and "I haven't been sleeping well lately". Each response was on five point scale from 1 (I totally disagree to it) to 5 (I totally agree to it). That is, the high score means that he perceives stress more.

\section{Assessment of Drinking}

The authors obtain the drinking habit of the respondents using answers to the question "Do you drink alcoholic beverages?". It was measured by six point ordinal scale, such as 1) if "Don't drink at all" ( $\mathrm{N}=1287), 2)$ if "Hardly drink" ( $\mathrm{N}=$ $1240), 3)$ if "Drink sometimes" $(\mathrm{N}=1385), 4)$ if "A can of beer or its equivalent a day, everyday" $(\mathrm{N}=828), 5)$ if "Three cans of beer or its equivalent a day, everyday" $(\mathrm{N}=550)$, and 6$)$ if "Five cans of beer or its equivalent a day, everyday" $(\mathrm{N}=79)$.

\section{Results}

\section{Time-Discount Rate across Generations}

The samples sizes for different age groups ("generations") are presented in Table 2. Time-discount rate (logged gross time-discount rate) over generations of men and women are presented in Figures 1(a) and (b), respectively. Correlations between time-discount rate and other variables are presented in Tables 3(a)-(l), by generations. Though not tested statistically,
Table 2.

Number of subjects by generation.

\begin{tabular}{cccc}
\hline Generations & Male & Female & Total \\
\hline $20-29$ & 64 & 113 & 177 \\
$30-39$ & 152 & 287 & 439 \\
$40-49$ & 269 & 495 & 764 \\
$50-59$ & 325 & 499 & 824 \\
$60-69$ & 363 & 525 & 888 \\
$70-79$ & 162 & 196 & 358 \\
Total & 1335 & 2115 & 3450 \\
\hline
\end{tabular}

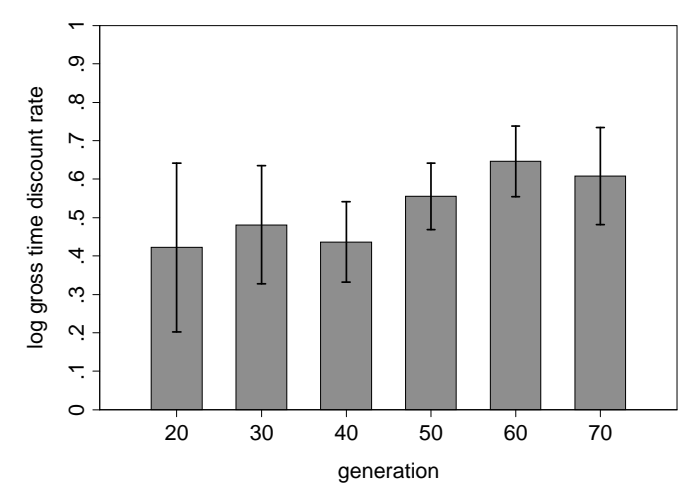

(a)

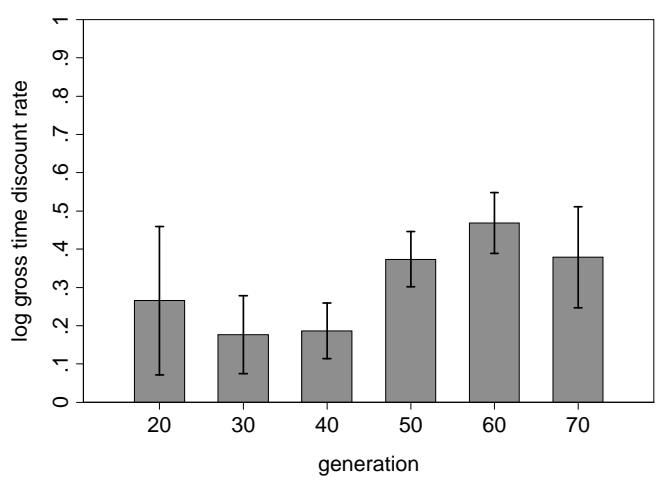

(b)

Figure 1.

(a) Time-discount rate of men; (b) Time-discount rate of women.

the readers can see that men and women had highest time-discount rate in their sixties (Figures 1(a) and (b)). Furthermore, men generally had higher time-discount rate than women within all generations.

\section{Education and Time-Discount Rate}

First, the authors examine the relationship between timediscount rate and education. It was observed significant negative correlations between education level and time-discounting of men aged 40 - 49 (Table 3(c)) and women aged 50 - 59 (Table $3(\mathbf{j})$ ). Although the correlations between education level and time-discount rate were not always significant, the direction of the effect of education level on time-discounting were mostly negative, consistent with previous studies indicating that more educated people are more patient in intertemporal choice (Kirby et al., 2005). It is to be noted that this effect of education level on time-discount rate is not because more educated people smoke less. The present subjects were all non-smokers. 
Table 3.

(a) Men aged 20 - 29 ( $\mathrm{N}=64)$; (b) Men aged 30 - 39 ( $\mathrm{N}=152)$; (c) Men aged 40 - 49 ( $\mathrm{N}=269)$; (d) Men aged 50 - 59 ( $\mathrm{N}=325)$; (e) Men aged 60 $69(\mathrm{~N}=363)$; (f) Men aged $70-79(\mathrm{~N}=162)$; (g) Women aged $20-29(\mathrm{~N}=113)$; (h) Women aged $30-39(\mathrm{~N}=287)$; (i) Women aged $40-49(\mathrm{~N}=$ 495); (j) Women aged 50 - $59(\mathrm{~N}=499)$; (k) Women aged 60 - $69(\mathrm{~N}=525)$; (l) Women aged $70-79(\mathrm{~N}=196)$.

(a)

\begin{tabular}{|c|c|c|c|c|c|c|c|}
\hline & $\begin{array}{c}\text { Time } \\
\text { discounting }\end{array}$ & Drinking & Education & Stress & Depression & Sleeplessness & Loneliness \\
\hline $\begin{array}{c}\text { Time } \\
\text { discounting }\end{array}$ & 1 & & & & & & \\
\hline Drinking & -.037 & 1 & & & & & \\
\hline Education & -.054 & .100 & 1 & & & & \\
\hline Stress & -.047 & .079 & .039 & 1 & & & \\
\hline Depress & .062 & -.038 & $-.052^{* * *}$ & .545 & 1 & & \\
\hline Sleepless & .074 & -.105 & $-.062^{* * *}$ & $.301^{* * *}$ & .348 & 1 & \\
\hline Loneliness & -.119 & -.073 & $.075^{* * *}$ & $.451^{* * *}$ & .678 & .241 & 1 \\
\hline
\end{tabular}

(b)

\begin{tabular}{|c|c|c|c|c|c|c|c|}
\hline & $\begin{array}{c}\text { Time } \\
\text { discounting }\end{array}$ & Drinking & Education & Stress & Depression & Sleeplessness & Loneliness \\
\hline $\begin{array}{c}\text { Time } \\
\text { discounting }\end{array}$ & 1 & & & & & & \\
\hline Education & -.153 & -.024 & 1 & & & & \\
\hline Stress & -.005 & .076 & -.077 & 1 & & & \\
\hline Depress & .041 & .035 & $-.024^{* * *}$ & .645 & 1 & & \\
\hline Sleepless & -.071 & $-.028^{*}$ & $-.137^{* * *}$ & $.345^{* * *}$ & .496 & 1 & \\
\hline Loneliness & .035 & -.015 & $-.036^{* * *}$ & $.358^{* * *}$ & $.571^{* * *}$ & .445 & 1 \\
\hline
\end{tabular}

(c)

\begin{tabular}{|c|c|c|c|c|c|c|c|}
\hline & $\begin{array}{c}\text { Time } \\
\text { discounting }\end{array}$ & Drinking & Education & Stress & Depression & Sleeplessness & Loneliness \\
\hline $\begin{array}{c}\text { Time } \\
\text { discounting }\end{array}$ & 1 & & & & & & \\
\hline Drinking & .015 & 1 & & & & & \\
\hline Education & $-.207^{* * *}$ & .151 & 1 & & & & \\
\hline Stress & .007 & .052 & -.021 & 1 & & & \\
\hline Depress & .044 & -.055 & $-.006^{* * *}$ & .635 & 1 & & \\
\hline Sleepless & $-.014^{* * *}$ & -.19 & $-.065^{* * *}$ & $.337^{* * *}$ & .461 & 1 & \\
\hline Loneliness & -.009 & -.128 & $-.030^{* * *}$ & $.413^{* * *}$ & $.535^{* * *}$ & .432 & 1 \\
\hline
\end{tabular}

(d)

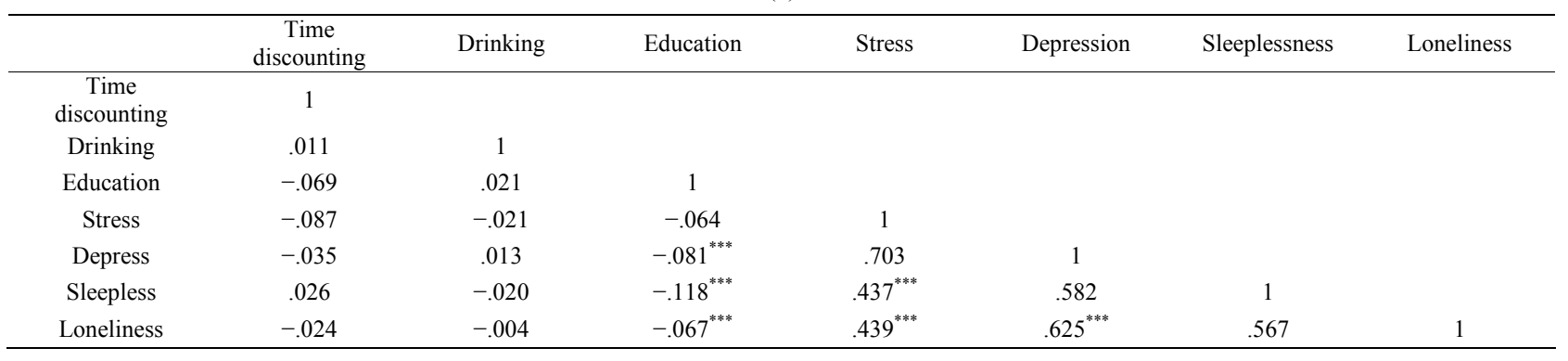

(e)

\begin{tabular}{|c|c|c|c|c|c|c|c|}
\hline & $\begin{array}{c}\text { Time } \\
\text { discounting }\end{array}$ & Drinking & Education & Stress & Depression & Sleeplessness & Loneliness \\
\hline $\begin{array}{c}\text { Time } \\
\text { discounting }\end{array}$ & 1 & & & & & & \\
\hline Education & .014 & .006 & 1 & & & & \\
\hline Stress & $-.096^{*}$ & -.092 & -.026 & 1 & & & \\
\hline Depress & -.019 & -.072 & $-.027^{* * *}$ & .684 & 1 & & \\
\hline Sleepless & .011 & .026 & $.005^{* * *}$ & $.334^{* * *}$ & .450 & 1 & \\
\hline Loneliness & .045 & -.040 & $-.017^{* * *}$ & $.385^{* * *}$ & $.564^{* * *}$ & .477 & 1 \\
\hline
\end{tabular}


S. YAMANE ET AL.

(f)

\begin{tabular}{|c|c|c|c|c|c|c|c|}
\hline & $\begin{array}{c}\text { Time } \\
\text { discounting }\end{array}$ & Drinking & Education & Stress & Depression & Sleeplessness & Loneliness \\
\hline $\begin{array}{c}\text { Time } \\
\text { discounting }\end{array}$ & 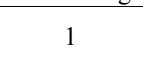 & & & & & & \\
\hline Drinking & -.134 & 1 & & & & & \\
\hline Education & -.023 & -.079 & 1 & & & & \\
\hline Stress & -.052 & -.099 & .031 & 1 & & & \\
\hline Depress & .032 & -.164 & $-.086^{* * *}$ & .648 & 1 & & \\
\hline Sleepless & .060 & -.160 & $-.115^{* * *}$ & $.391^{* * *}$ & .460 & 1 & \\
\hline Loneliness & .063 & $-.084^{*}$ & $-.126^{* * *}$ & $.549^{* * *}$ & $.669^{* * *}$ & .421 & 1 \\
\hline
\end{tabular}

(g)

\begin{tabular}{|c|c|c|c|c|c|c|c|}
\hline & $\begin{array}{c}\text { Time } \\
\text { discounting }\end{array}$ & Drinking & Education & Stress & Depression & Sleeplessness & Loneliness \\
\hline $\begin{array}{c}\text { Time } \\
\text { discounting }\end{array}$ & 1 & & & & & & \\
\hline Drinking & -.118 & 1 & & & & & \\
\hline Education & -.106 & .003 & 1 & & & & \\
\hline Stress & -.127 & .014 & .085 & 1 & & & \\
\hline Depress & -.114 & .117 & $.117^{* * *}$ & .665 & 1 & & \\
\hline Sleepless & -.015 & .054 & $-.044^{* * *}$ & $.520^{* * *}$ & .551 & 1 & \\
\hline Loneliness & .017 & $.067^{*}$ & $.147^{* * *}$ & $.380^{* * *}$ & $.535^{* * *}$ & .286 & 1 \\
\hline
\end{tabular}

(h)

\begin{tabular}{|c|c|c|c|c|c|c|c|}
\hline & $\begin{array}{c}\text { Time } \\
\text { discounting }\end{array}$ & Drinking & Education & Stress & Depression & Sleeplessness & Loneliness \\
\hline $\begin{array}{c}\text { Time } \\
\text { discounting }\end{array}$ & 1 & & & & & & \\
\hline Drinking & .005 & 1 & & & & & \\
\hline Education & -.058 & -.015 & 1 & & & & \\
\hline Stress & .027 & -.05 & .009 & 1 & & & \\
\hline Depress & .044 & -.07 & $-.091^{* * *}$ & .687 & 1 & & \\
\hline Sleepless & $.076^{*}$ & -.099 & $-.076^{* * *}$ & $.417^{* * *}$ & .561 & 1 & \\
\hline Loneliness & .030 & -.013 & $-.057^{* * *}$ & $.414^{* * *}$ & $.586^{* * *}$ & .483 & 1 \\
\hline
\end{tabular}

(i)

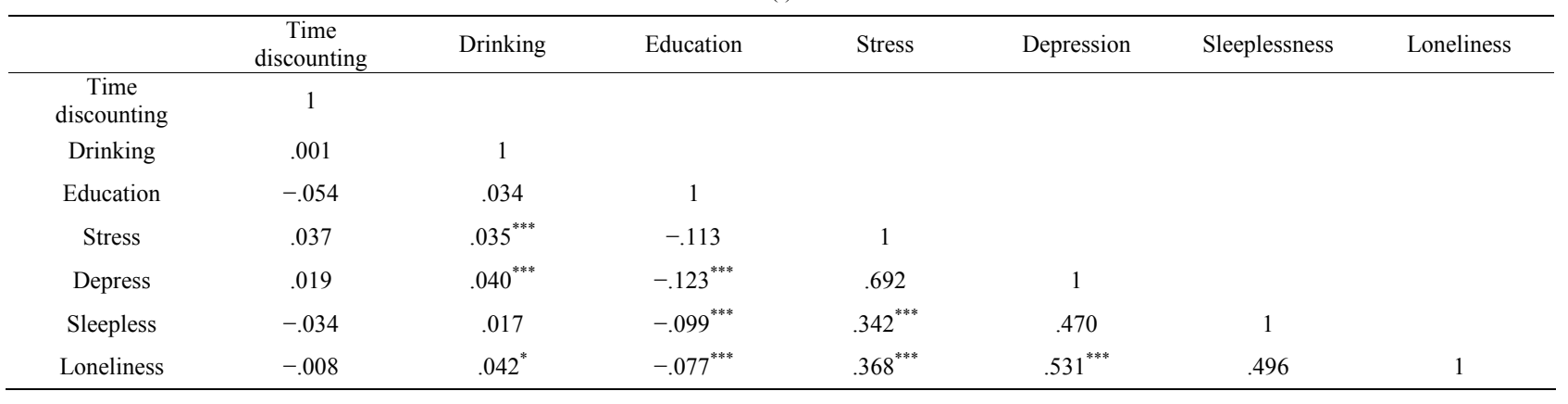

(j)

\begin{tabular}{|c|c|c|c|c|c|c|c|}
\hline & $\begin{array}{c}\text { Time } \\
\text { discounting }\end{array}$ & Drinking & Education & Stress & Depression & Sleeplessness & Loneliness \\
\hline $\begin{array}{c}\text { Time } \\
\text { discounting }\end{array}$ & 1 & & & & & & \\
\hline Drinking & -.046 & 1 & & & & & \\
\hline Education & $-.064^{* * *}$ & .128 & 1 & & & & \\
\hline Stress & -.072 & .016 & -.032 & 1 & & & \\
\hline Depress & -.030 & $-.015^{*}$ & $-.080^{* * *}$ & .740 & 1 & & \\
\hline Sleepless & .028 & $.034^{* * *}$ & $-.156^{* * *}$ & $.335^{* * *}$ & .462 & 1 & \\
\hline Loneliness & -.055 & -.034 & $-.026^{* * *}$ & $.425^{* * *}$ & $.514^{* * *}$ & .491 & 1 \\
\hline
\end{tabular}


S. YAMANE ET AL.

(k)

\begin{tabular}{|c|c|c|c|c|c|c|c|}
\hline & $\begin{array}{c}\text { Time } \\
\text { discounting }\end{array}$ & Drinking & Education & Stress & Depression & Sleeplessness & Loneliness \\
\hline $\begin{array}{c}\text { Time } \\
\text { discounting }\end{array}$ & 1 & & & & & & \\
\hline Drinking & -.011 & 1 & & & & & \\
\hline Education & -.076 & .056 & 1 & & & & \\
\hline Stress & .029 & & .015 & 1 & & & \\
\hline Depress & .062 & .035 & $-.022^{* * *}$ & .679 & 1 & & \\
\hline Sleepless & .074 & -.015 & $-.064^{* * *}$ & $.398^{* * *}$ & .531 & 1 & \\
\hline Loneliness & .069 & .030 & $-.017^{* * *}$ & $.433^{* * *}$ & $.607^{* * *}$ & .527 & 1 \\
\hline
\end{tabular}

(1)

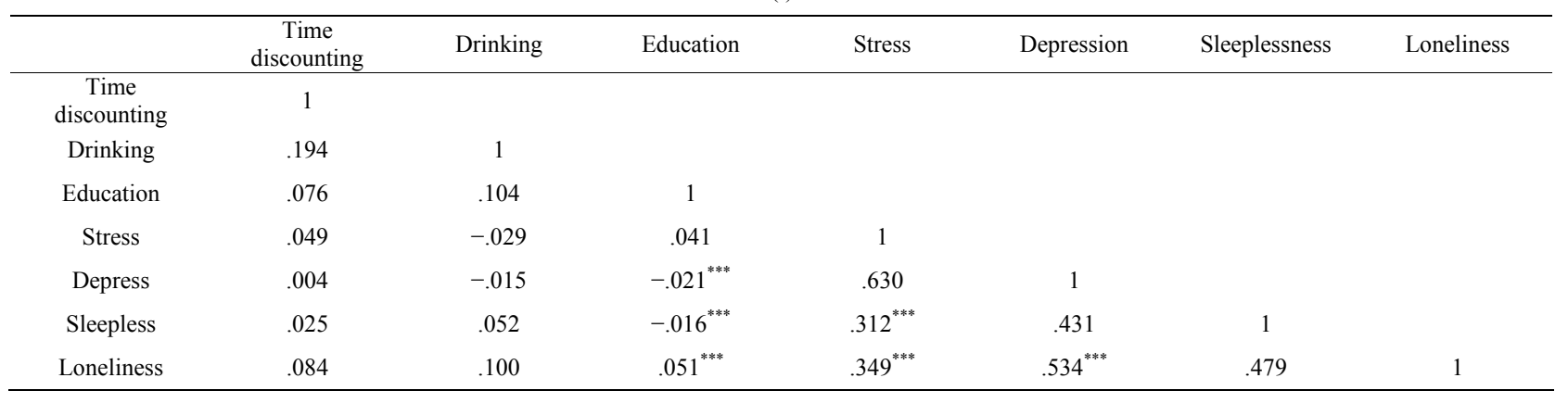

\section{Socio-Emotional Status and Time-Discount Rate}

Next, the authors performed correlation analysis between socio-emotional status (i.e., depression, stress, loneliness) and time-discounting. It was observed that stress was negatively related to time-discount rate of men aged 60 - 69 (Table 3(e)), indicating that relatively old men with high perceived stress are less impulsive in intertemporal choice. Other factors of socioemotional status (i.e., depression, loneliness) were not significantly related to time-discount rate for all generations.

\section{Sleeplessness and Time-Discount Rate}

The authors then analyzed the relationship between sleeplessness and time-discount rate, to examine the role of the quality of sleep in impulsivity in intertemporal choice. It was found that sleeplessness had opposite effects on time-discount rate between men and women; i.e., sleeplessness was negatively and positively associated with time-discount rate of men aged 40 49 (Table 3(c)) and women aged 30 - 39 (Table 3(h)), respectively.

\section{Drinking and Time-Discount Rate}

Because time-discount rate is related to the intake of addictive drugs (Bickel \& Marsch, 2001) in drug-dependent subjects, the authors examined the relationship between alcohol intake and time-discounting in the present non-alcoholic population. The authors observed no significant relationship between drinking and time-discount rate for gain. This indicates that alcohol intake by non-alcoholic subjects does not significantly relate to impulsivity in intertemporal choice for gain, consistent with our previous study with Japanese university students, reporting that alcohol intake was only related to procrastination (i.e., temporal discounting of loss), but not impulsivity (i.e., temporal discounting of gain) in non-alcoholic students (Takahashi, Ohmura, Oono, \& Radford, 2009).

\section{Discussion}

To our knowledge, this is the first study to demonstrate that 1) both men and women have the highest time-discount rate in their $60 \mathrm{~s} ; 2$ ) education has a negative impact on time-discount rate of men aged 40 - 49 and women aged $50-59 ; 3$ ) perceived stress has a negative impact on time-discount rate of men aged 60 - 69; and 4) sleeplessness has negative and positive impacts on time-discount rate of men aged 40 - 49 and women aged 30 39 , respectively, in a multi-generational Japanese population. Also, it was observed that men were generally more impulsive in intertemporal choice than women, consistent with a previous study with American subjects (Kirby \& Markovic, 1996). Furthermore, alcohol intake did not influence intertemporal choice for gain by the present Japanese subjects, consistent with our previous study with non-alcoholic Japanese university students (Takahashi et al., 2009) which demonstrated that alcohol use is related to temporal discounting of loss, but unrelated to temporal discounting of gain.

It is also to be underscored that our present Japanese sample did not include habitual smokers, which can exclude our previously-reported dose-dependent effect of nicotine intake on intertemporal choice by Japanese subjects (Ohmura et al., 2005). These findings have some implications for behavioral economics and neuroeconomics, as well as evolutionary biology and economics, which are addressed below.

Some behavioral economic and/or psychological studies suggests that adult human time-discount rates decline monotonically over the life course and are much lower by age seventy than in young adulthood (e.g., Green, Myerson, \& Ostaszewski, 1999). A recent developmental psychological study also reported that children's time-discount rate decreases according to their age (Steinberg et al., 2009). Evolutionary psychologists Daly and Wilson (2005) questioned the evolutionary biological foundations of the age-dependence of time-discount rate. An evolutionary economist Rogers (1994) has argued that the 
age-dependence of human time and risk preference is optimally determined by intergenerational resource transfers and the effects of personal reputation on the fitness prospects of family members. Our present finding that humans are most impulsive in their $60 \mathrm{~s}$ irrespective of sex should be taken into account in these evolutionary economic and biological studies.

As stated earlier, it makes an economic sense that education is related to a reduction in time-discount rate (Becker \& Mulligan, 1997). The presently-observed negative relationships between education and time-discount rate of men in $40 \mathrm{~s}$ and women in $50 \mathrm{~s}$ are consistent with the economic theory. The reason why a strong negative effect of education on time-discount rate did not exist in other generations should further be examined in future behavioral economic studies in relation to changes in Japanese educational systems.

There was a negative correlation between perceived stress and time-discount rate of men in their $60 \mathrm{~s}$, but not of women in the same age range. This is consistent with our previous neuroeconomic studies which demonstrated that a cortisol (a stress steroid hormone) level had a negative impact on time-discount rate of men (Takahashi, 2004) but not in women (Takahashi et al., 2010). In our previous study (Takahashi et al., 2010), however, another biological marker of stress (i.e., salivary alphaamylase) was negatively related to time-discount rate, irrespective of subject's sex. It is therefore possible that the presently-assessed "perceived stress" is more strongly related to chronic activation of HPA system, rather than SAM system. This issue should be examined in future studies on the relationship between negative affect and economic decision-making. On the other hand, loneliness and depression did not dramatically affect time-discount rate in the present non-clinical subjects. Our previous study (Takahashi et al., 2008a) reported that clinically depressed subjects had higher time-discount rate in the near future. It is therefore important to ask the distinction between non-clinical and clinical states of being depressed among healthy and clinical subjects.

Consistent with previous laboratory experimental studies (Acheson et al., 2007; Reynolds \& Schiffbauer, 2004b), sleeplessness tended to enhance women's time-discount rate in their $30 \mathrm{~s}$. In contrast, sleeplessness was negatively related to men's time-discount rate in their $40 \mathrm{~s}$. A recent neurobiological study demonstrated that sleep deprivation has more detrimental effect on cognitive performance in female rats, in comparison to male rats (Hajali, Sheibani, Esmaeili-Mahani, \& Shabani, 2012). Therefore, it may be conceivable that there are neurobiological sex differences in the relationships between sleep deprivation and impulsivity in intertemporal choice. Another possibility is that sleeplessness is related to differences in socioeconomic status in men aged 40 - 49. These possibilities should more extensively be studied in future economic research.

In line with evolutionary biological theory (Daly \& Wilson, 2005) and an experimental study (Kirby \& Markovic, 1996), the present study revealed that men were generally more impulsive than women in intertemporal choice. This gender difference is not due to a difference in smoking status between men and women, because our present subjects were non-smokers. Our previous neuroeconomic study demonstrated that testosterone (a male steroid hormone) is nonlinearly related to time-discount rate (Takahashi et al., 2006). A more recent study by labor economists also reported a nonlinear relationship between testosterone and risk-aversion in women (Sapienza, Zingales, \& Maestripieri, 2009). Taken together, studies in neu- roeconomics should examine the roles of sex steroid hormones, in addition to stress steroid hormones, in determining a gender difference in economic decision-making across generations.

Apart from the main objectives of the present study, it is striking that education markedly reduces negative affect such as depression and loneliness in most generations (though there are some exceptions). Future studies in economics of education should pursuit this effect of education on emotion, in order to further establish the relationships between education and happiness.

Concerning the relationship between age and temporal discounting, the roles of anticipatory time-perception and responsivity of brain reward systems (e.g., the striatum) have recently been attracting much attention (Löckenhoff, 2011; Löckenhoff et al., 2011). Our previous studies indicate that anticipatory time-perception may be related to impulsivity in temporal discounting behavior (Takahashi, 2005; Takahashi et al., 2008). It is therefore important to examine the role of age-dependency of time-perception in intertemporal choice, in future behavioral economic studies. Moreover, it is known that there are some "anomalies" in intertemporal choice (e.g., hyperbolic discounting, sign effect, subadditive discounting, delay-speedup asymmetry, and interval effect) (Frederick, Shane, Loewenstein, \& O’Donoghue, 2002; Kinari, Ohtake, \& Tsutsui, 2009; Scholten $\&$ Read, 2010; Takahashi, 2009). Future studies in behavioral economics should examine whether these anomalies in intertemporal choice are related to socio-emotional status, age, and education.

It is now discussed that several limitations exist in the present study. First, the present study only examined Japanese population. Drinking and smoking habit differ across societies and cultures, future studies should examine other populations. Second, biological markers of stress and depression (e.g., cortisol and serotonin) were not examined in the present study. Future studies should examine the roles of neurobiological markers in the relationships between emotion, demographics, and impulsivity in intertemporal choice, to help us to develop neuroeconomic understandings of human intertemporal choice.

\section{REFERENCES}

Acheson, A., Richards, J. B., \& de Wit, H. (2007). Effects of sleep deprivation on impulsive behaviors in men and women. Physiology \& Behavior, 91, 579-587. doi:10.1016/j.physbeh.2007.03.020

Arulampalam, W., Booth, A. L., \& Bryan, M. L. (2007). Is there a glass ceiling over Europe? Exploring the gender pay gap across the wages distribution. Industrial and Labor Relations Review, 60, 163-186.

Azmat, G., Guell, M., \& Manning, A. (2006). Gender gaps in unemployment rates in OECD countries. Journal of Labor Economics, 24, 1-37. doi: $10.1086 / 497817$

Becker, G. S., \& Mulligan, C. B. (1997). The endogenous determination of time preference. Quarterly Journal of Economics, 112, 729 758. doi:10.1162/003355397555334

Berns, G. S., Laibson, D., \& Loewenstein, G. (2007). Intertemporal choice: Toward an integrative framework. Trends in Cognitive Sciences, 11, 482-488. doi:10.1016/j.tics.2007.08.011

Bickel, W. K., \& Marsch, L. A. (2001). Toward a behavioral economic understanding of drug dependence: Delay discounting processes. Addiction, 96, 73-86. doi:10.1046/j.1360-0443.2001.961736.x

Bonsang, E., Adam, S., \& Perelman, S. (2012). Does retirement affect cognitive functioning? Journal of Health Economics, 31, 490-501. doi:10.1016/j.jhealeco.2012.03.005

Chabris, C. F., Laibson, D., Morris, C. L., Schuldt, J. P., \& Taubinsky, D. (2008). Individual laboratory-measured discount rates predict 
field behavior. Journal of Risk and Uncertainty, 37, 237-269. doi:10.1007/s11166-008-9053-x

Coe, N. B., \& Zamarro, G., (2011). Retirement effects on health in Europe. Journal of Health Economics, 30, 77-86. doi:10.1016/j.jhealeco.2010.11.002

Daly, M., \& Wilson, M. (2005). Carpe diem: Adaptation and devaluing the future. The Quarterly Review of Biology, 80, 55-61. doi:10.1086/431025

Ernst, M. (2012). The usefulness of neuroeconomics for the study of depression across adolescence into adulthood. Biological Psychiatry, 72, 84-86. doi:10.1016/j.biopsych.2012.02.027

Fehr-Duda, H., De Gennaro, M., \& Schubert, R. (2006). Gender, financial risk, and probability weights. Theory and Decision, 60, 283-313. doi:10.1007/s11238-005-4590-0

Frederick, S., Loewenstein, G., \& O’Donoghue, T. (2002). Time discounting and time preference: A critical review. Journal of Economic Literature, 40, 351-401. doi:10.1257/002205102320161311

Fujisawa, T. X., Nishitani, S., Ishii, S., \& Shinohara, K. (2011). Differential modulation of impulsive behavior by loneliness and testosterone in adolescent females. Neuro Endocrinology Letters, 32, 836840.

Green, L., Fry, A. F., \& Myerson, J. (1994). Discounting of delayed rewards: A life-span comparison. Psychological Science, 5, 33-36. doi:10.1111/j.1467-9280.1994.tb00610.x

Green, L., Myerson, J., \& Ostaszewski, P. (1999). Discounting of delayed rewards across the life span: Age differences in individual discounting functions. Behavioural Processes, 46, 89-96. doi:10.1016/S0376-6357(99)00021-2

Hajali, V., Sheibani, V., Esmaeili-Mahani, S., \& Shabani, M. (2012). Female rats are more susceptible to the deleterious effects of paradoxical sleep deprivation on cognitive performance. Behavioural Brain Research, 228, 311-318. doi:10.1016/j.bbr.2011.12.008

Ifcher, J., \& Zarghamee, H. (2011). Happiness and time preference: The effect of positive affect in a random-assignment experiment. American Economic Review, 101, 3109-3129. doi:10.1257/aer.101.7.3109

Ikeda, S., Kang, M. I., \& Ohtake, F. (2010). Hyperbolic discounting, the sign effect, and the body mass index. Journal of Health Economics, 29, 268-284. doi:10.1016/i.jhealeco.2010.01.002

Kimball, M. S., Sahm, C. R., \& Shapiro, M. D. (2008). Imputing risk tolerance from survey responses. Journal of the American Statistical Association, 103, 1028-1038. doi:10.1198/016214508000000139

Kimmo, K., \& Brent, S. (2010). Emotional reactions to losing explain gender differences in entering a risky lottery. Judgment and Decision Making, 5, 159-163.

Kinari, Y., Ohtake, F., \& Tsutsui, Y. (2009). Time discounting: Declining impatience and interval effect. Journal of Risk and Uncertainty, 39, 87-112. doi:10.1007/s11166-009-9073-1

Kirby, K. N., \& Marakovic, N. N. (1996). Delay-discounting probabilistic rewards: Rates decrease as amounts increase. Psychonomic Bulletin \& Review, 3, 100-104. doi:10.3758/BF03210748

Kirby, C., Winston, G., \& Santiesteban, M. (2005). Impatience and grades: Delay-discount rates correlate negatively with college GPA. Learning and Individual Differences, 15, 213-222. doi:10.1016/j.lindif.2005.01.003

Löckenhoff, C. E. (2011). Age, time, and decision making: from processing speed to global time horizons. Annals of the New York Academy of Sciences, 1235, 44-56. doi:10.1111/j.1749-6632.2011.06209.x

Löckenhoff, C. E., O’Donoghue, T., \& Dunning, D. (2011). Age differences in temporal discounting: The role of dispositional affect and anticipated emotions. Psychology and Aging, 26, 274-284. doi: $10.1037 / \mathrm{a} 0023280$

Loewenstein, G. (1996). Out of control: Visceral influences on behavior. Organizational Behavior and Human Decision Processes, 65, 272-292. doi:10.1006/obhd.1996.0028

Loewenstein, G., Rick, S., \& Cohen, J. D. (2008). Neuroeconomics. Annual Review of Psychology, 59, 647-672. doi:10.1146/annurev.psych.59.103006.093710

McClure, S. M., Laibson, D. I., Loewenstein, G., \& Cohen, J. D. (2004). Separate neural systems value immediate and delayed monetary re- wards. Science, 306, 503-507. doi:10.1126/science.1100907

Menz, M. M., Buchel, C., \& Peters, J. (2012). Sleep deprivation is associated with attenuated parametric valuation and control signals in the midbrain during value-based decision making. The Journal of Neuroscience, 32, 6937-6946. doi:10.1523/JNEUROSCI.3553-11.2012

Ohmura, Y., Takahashi, T., \& Kitamura, N. (2005). Discounting delayed and probabilistic monetary gains and losses by smokers of cigarette. Psychopharmacology, 182, 508-515. doi: 10.1007/s00213-005-0110-8

Peters, J., \& Büchel, C. (2010). Episodic future thinking reduces reward delay discounting through an enhancement of prefrontal-mediotemporal interactions. Neuron, 66, 138-148. doi:10.1016/j.neuron.2010.03.026

Phillips, P. E., Kim, J. J., \& Lee, D. (2012). Neuroeconomics. Frontiers in Behavioral Neuroscience, 6 . doi:10.3389/fnbeh.2012.00015

Read, D., \& Read, N. L. (2004). Time discounting over the lifespan. Organizational Behavior and Human Decision Processes, 94, 22-32. doi:10.1016/j.obhdp.2004.01.002

Reynolds, B., \& Schiffbauer, R. M. (2004a). Impulsive choice and workplace safety: A new area of inquiry for research in occupational settings. The Behavior Analyst, 27, 239-246.

Reynolds, B., \& Schiffbauer, R. (2004b). Measuring state changes in human delay discounting: An experiential discounting task. Behavioural Processes, 67, 343-356.

Rogers, A. R. (1994). Evolution of time preference by natural selection. American Economic Review, 84, 460-481.

Sapienza, P., Zingales, L., \& Maestripieri, D. (2009). Gender differences in financial risk aversion and career choices are affected by testosterone. Proceedings of the National Academy of Sciences, 106, 15268-15273. doi:10.1073/pnas.0907352106

Scholten, M., \& Read, D. (2010). The psychology of intertemporal tradeoffs. Psychological Review, 117, 925-944. doi:10.1037/a0019619

Schweighofer, N., Bertin, M., Shishida, K., Okamoto, Y., Tanaka, S. C., Yamawaki, S., \& Doya, K. (2008). Low-serotonin levels increase delayed reward discounting in humans. The Journal of Neuroscience, 28, 4528-4532. doi:10.1523/JNEUROSCI.4982-07.2008

Steinberg, L., Graham, S., O’Brien, L., Woolard, J., Cauffman, E., \& Banish, M. (2009). Age differences in future orientation and delay discounting. Child Development, 80, 28-44. doi:10.1111/j.1467-8624.2008.01244.x

Takahashi, T. (2004). Cortisol levels and time-discounting of monetary gain in humans. Neuroreport, 15, 2145-2147. doi:10.1097/00001756-200409150-00029

Takahashi, T. (2005). Loss of self-control in intertemporal choice may be attributable to logarithmic time-perception. Medical Hypotheses, 65, 691-693. doi:10.1016/j.mehy.2005.04.040

Takahashi, T. (2009). Theoretical frameworks for neuroeconomics of intertemporal choice. Journal of Neuroscience, Psychology, and Economics, 2, 75-90. doi:10.1037/a0015463

Takahashi, T., Ohmura, Y., Oono, H., \& Radford, M. (2009). Alcohol use and discounting of delayed and probabilistic gain and loss. Neuroendocrinology Letters, 30, 749-752.

Takahashi, T., Oono, H., Inoue, T., Boku, S., Kako, Y., Kitaichi, Y., Kusumi, I., Masui, T., Nakagawa, S., Suzuki, K., Tanaka, T., Koyama, T., \& Radford, M. H. (2008a). Depressive patients are more impulsive and inconsistent in intertemporal choice behavior for monetary gain and loss than healthy subjects - An analysis based on Tsallis' statistics. Neuroendocrinology Letters, 29, 351-358.

Takahashi, T., Oono, H., \& Radford, M. H. (2008b). Psychophysics of time perception and intertemporal choice models. Physica A, 387, 2066-2074. doi:10.1016/j.physa.2007.11.047

Takahashi, T., Sakaguchi, K., Oki, M., Homma, S., \& Hasegawa, T. (2006). Testosterone levels and discounting delayed monetary gains and losses in male humans. Neuroendocrinology Letters, 27, 439444.

Takahashi, T., Shinada, M., Inukai, K., Tanida, S., Takahashi, C., Mifune, N., Takagishi, H., Horita, Y., Hashimoto, H., Yokota, K., Kameda, T., \& Yamagishi, T. (2010). Stress hormones predict hyper- 


\section{S. YAMANE ET AL.}

bolic time-discount rates six months later in adults. Neuroendocrinology Letters, 31, 616-621.

Venkatraman, V., Huettel, S. A., Chuah, L. Y., Payne, J. W., \& Chee,
M. W. (2011). Sleep deprivation biases the neural mechanisms underlying economic preferences. The Journal of Neuroscience, 31, 3712-3718. doi:10.1523/JNEUROSCI.4407-10.2011 